\title{
CADÁVERES, VAGALUMES, FOGOS-FÁTUOS
}

\author{
EDUARDO STERZI reflete sobre o conceito de sobrevivência nas artes a \\ partir da leitura das obras de Pasolini e Didi-Huberman
}

Pier Paolo Pasolini se convertirá en el Santo Patrón de la Fuga en el año 2100.

Roberto Bolaño, Amuleto (1999)

Pasolini passou aqui.

Gabriel Kerhart, pichação na fachada do cinema Belas Artes, fechado em março de 2011

1. Duas obras cruciais da literatura contemporânea - de um lado, um volume de gênero indeterminado, situado entre o romance e o ensaio, entre a memória e a reportagem, escrito por um jovem italiano; de outro, o mais recente livro de um dos principais poetas brasileiros da atualidade - fazem coincidir momentos decisivos de suas tessituras com invocações explícitas das palavras, das imagens e sobretudo da figura do escritor e cineasta Pier Paolo Pasolini.

A primeira invocação a que me refiro encontra-se nas páginas iniciais da segunda das duas partes de Gomorra, de Roberto Saviano, publicado em 2006. Recordamse, ali, as circunstâncias da morte, num acidente de trabalho, de Francesco Iacomino, operário da construção civil de Ercolano. Como os canteiros de obras da região são controlados pela Camorra, a organização criminosa que domina Nápoles e arredores, os companheiros de Iacomino fugiram do local do acidente sem nem mesmo chamar o socorro médico. O corpo foi deixado no meio da rua, agonizante, expelindo sangue dos pulmões. Estava longe de ser uma morte excepcional: como observa Saviano, era apenas mais «um dos trezentos operários que se arrebentavam todo ano nos canteiros da Itália». Mas, para a sensibilidade política e ética do escritor, um limite fora ultrapassado:

Com a morte de Iacomino, desencadeou-se em mim uma raiva daquelas que se assemelham mais a um ataque de asma do que a uma crise nervosa. Gostaria de fazer como o protagonista de $A$ vida acre [La vita agra] de Luciano Bianciardi que chega a Milão com a vontade de explodir o Pirellone [à época, edifício-sede da Pirelli; desde 1978, sede da administração regional da Lombardia] para vingar os quarenta e oito mineiros de Ribolla, massacrados por uma explosão, em maio de 1954, no poço Camorra.

Chamado assim pelas infames condições de trabalho. Também eu devia, 


celeuna número $1 \mid$ volume 1 maio $2013 \quad$ dossiê

talvez, escolher um prédio, o Prédio, para explodir, mas ainda antes de enfiar-me na esquizofrenia do terrorista [attentatore], logo que entrei na crise asmática de raiva retumbou nos meus ouvidos o Eu sei [Io so] de Pasolini como um jingle musical que se repetia até a obsessão [sino allassillo]. E assim, em vez de esmiuçar prédios a explodir, fui a Casarsa, até o túmulo de Pasolini.[1]

«Eu sei» - a fórmula pasoliniana evocada por Saviano - é a primeira frase, logo repetida anaforicamente na abertura dos onze seguintes parágrafos, de um artigo publicado no Corriere della Sera em 14 de novembro de 1974, um ano antes de Pasolini ser assassinado. Neste texto, que se intitulou originalmente «O que é este golpe?» («Che cosè questo golpe?») e hoje é conhecido pelo título que ganhou nos Escritos corsários, «O romance das matanças» («Il romanzo delle stragi»), Pasolini, em tom profético, dizia saber «os nomes dos responsáveis» pela violenta instabilidade política na Itália daqueles últimos anos, a começar pelos atentados cometidos em 1969 e em 1974, por meio dos quais se buscava gerar medo na população e justificar a adoção de medidas de exceção:

Eu sei os nomes dos responsáveis pela matança de Milão em 12 de dezembro de 1969

Eu sei os nomes dos responsáveis pelas matanças de Bréscia e de Bolonha nos primeiros meses de 1974.

Eu sei os nomes da "cúpula" ["vertice"] que manobrou, sejam os velhos fascistas idealizadores de golpes, sejam os neofascistas autores materiais das primeiras matanças, sejam, enfim, os "desconhecidos" autores materiais das matanças mais recentes. [2]

Pasolini dizia saber «os nomes do grupo de poderosos» que, com a colaboração da CIA, dos coronéis gregos e da máfia, manipulavam e acobertavam, «entre uma missa e outra» (alusão aos democratas-cristãos), «velhos generais», «jovens neofascistas, ou antes neonazistas» e até mesmo «criminosos comuns» - todos convertidos em peças de um grande e intrincado xadrez político-criminal. Este conhecimento que Pasolini cristaliza na fórmula relembrada por Saviano revela-se trágico, em certo sentido, na medida em que não pode se transformar em ação, a não ser no âmbito, restrito mas por isso mesmo potente, da escrita, da literatura:

Eu sei. Mas não tenho as provas. Não tenho nem ao menos indícios.

\footnotetext{
1. SAVIANO, Roberto. Gomorra. Viaggio nell'impero economico e nel sogno di dominio della camorra. Milão: Mondadori, 2006, p. 232.

2. PASOLINI, Pier Paolo, «Il romanzo delle stragi» (1974), In Scritti corsari (1975), hoje em Saggi sulla politica e sulla società (1999), org. Walter Siti e Silvia De Laude. Milão: Mondadori, 2009, p. 362.
} 
Eu sei porque sou um intelectual, um escritor, que busca acompanhar tudo o que acontece, conhecer tudo o que se escreve, imaginar tudo o que não se sabe ou que se cala; que coordena fatos mesmo distantes, que põe juntos os pedaços desorganizados e fragmentários de um inteiro e coerente quadro político, que restabelece a lógica lá onde parecem reinar a arbitrariedade, a loucura e o mistério.[3]

Podemos dizer, então, que, para Pasolini - mas também para Saviano -, Eu sei é o nome de um intervalo trágico entre conhecimento e ação (intervalo propício para a imaginação, que pode saber «tudo o que não se sabe» e pode falar tudo o «que se cala»); Eu sei é, pois, a senha de um saber que tenta extrair alguma potência de sua própria impotência (o que talvez seja o paradoxo fundamental de toda arte frente ao real).[4] Saviano também sabe «os nomes dos responsáveis» pela morte de Francesco Iacomino e de todas as outras vítimas da Camorra - e escreve seu livro precisamente para decliná-los, coordenando «fatos [...] distantes» (os negócios da Camorra, como ele demonstra com relatos exemplares, embora enraizados em Nápoles ou Casal di Principe, acabam por se estender a todos os continentes), pondo juntos "pedaços desorganizados e fragmentários» de modo a formar um quadro complexo mas coeso, restabelecendo «a lógica lá onde parecem reinar a arbitrariedade, a loucura e o mistério». O próprio Saviano explica em termos de uma conquista da «possibilidade de escrever» a sua viagem a Casarsa:

Fui ao túmulo de Pasolini não para uma homenagem, tampouco para uma celebração. [...] Fui para encontrar um lugar. Um lugar onde fosse ainda possível refletir sem vergonha sobre a possibilidade da palavra. A possibilidade de escrever sobre os mecanismos do poder, para além das histórias, além dos detalhes. Refletir se era ainda possível dar os nomes [fare i nomi], um a um, indicar as faces, despir os corpos dos delitos e devolvê-los à condição de elementos da arquitetura da autoridade. Se era ainda possível seguir como porcos atrás de tartufo as dinâmicas do real, a afirmação dos poderes, sem metáforas, sem mediações, com a lâmina única da escrita.[5]

2. A segunda invocação a Pasolini que tenho em mente aparece na última página do livro Monodrama, de Carlito Azevedo, publicado em 2009 - mais precisamente, no parágrafo final do estupendo poema em prosa «H.», no

\footnotetext{
3. Id., p.363.

4. Como exemplo dessa potência extraída da impotência, podemos lembrar que «a reconstrução da verdade a propósito do que aconteceu na Itália depois de 1968» - reconstrução que, frisa Pasolini, «não é tão difícil», pelo menos quando se conta com a imaginação - estava na base de Petróleo (Petrolio), romance que ele vinha escrevendo por aqueles dias e que a sua morte deixaria incompleto (só tendo sido publicado, postumamente, em 1992)

5. SAVIANO, Roberto. Gomorra cit., p. 233
} 
qual o poeta relembra os últimos dias e a morte de sua mãe, assim como as suas primeiras reações à ausência dela. Neste parágrafo derradeiro, Carlito tenta imaginar o que lhe diria sua mãe se indagada se «lhe coube a morte boa ou a morte má». A resposta que a imaginação lhe oferece não é exatamente reconfortante, mas tampouco desesperadora:
- Comparada com a larga eternidade de nada sentir, nada provar, nada tocar, ver e ouvir que nos espera, a morte no sono, como dizem que coube a Chaplin, vale o que valem as dez costelas partidas, as orelhas arrancadas, os dedos decepados, a laceração horrível entre o pescoço e a nuca, a equimose larga e profunda nos testículos, o fígado lacerado, o coração lacerado, o rosto inchado irreconhecível, os hematomas, última forma física assumida por Pasolini nesse louco planeta que agora, para você, gira também sem $\operatorname{mim} .[6]$

Numa primeira leitura, talvez não se veja aí mais do que uma afirmação desencantada da profunda indiferença entre todas as modalidades de morte, uma vez que a qualquer delas se segue o mesmo nada devastador. Porém, esta não seria uma interpretação condizente com a complexidade retórica do poema. É preciso notar sobretudo, numa segunda leitura, que aqui estamos perante uma voz que, pelo menos na imaginação, desgarra-se da morte para dirigir-se a um vivo (aquele «você» enfatizado pela melodia e pela sintaxe, próximo ao final da longa frase), cobrando-lhe tacitamente, antes de tudo, o reconhecimento dessa sobrevivência espectral. Só assim se pode apreender o significado da invocação de Pasolini neste texto. Do ponto de vista estabelecido por Carlito[7], Pasolini parece ser - mais que uma vítima da «morte má», a qual, enfim, pelo menos do ponto de vista dos mortos, termina por equivaler à «morte boa» - o nome de uma forma de potência que não apenas consegue vencer a própria impotência, mas que, na memória e na imaginação dos vivos, resiste mesmo à mais dolorosa destruição.[8] Afinal, como sugere a comparação proposta no poema, mesmo a morte (boa ou má, tranqüila ou dolorosa) é uma forma - extrema, é certo - de experiência: isto é, uma forma de ainda (mesmo que pela última vez) sentir, provar, tocar, ver, ouvir. Neste sentido, pode-se dizer que a imagem de Pasolini morto «vale o que

\footnotetext{
6. AZEVEDO, Carlito. «H.», em Monodrama. Rio de Janeiro: 7Letras, 2009, p. 152. O nome de Pasolini também aparece em outro poema do mesmo livro: «A foto do santuário de Delfos / no Édipo de Pasolini / colada no painel do seu carro / no espelho do banheiro / e na caixa de remédios / me repete / que você não é mais triste / do que qualquer pessoa / que eu conheça / nesta cidade / de imigrantes / fantasmas / à sombra / do obsessor» («Monodrama», id., p. 99).

7. Que, sutilmente (consciente ou inconscientemente, o que não importa), parece cifrar o desejo de uma «morte boa» para si mesmo na alusão a Chaplin, cujo personagem mais notório, como se sabe, é conhecido no Brasil como Carlitos - portanto, um quase homônimo do poeta.
}

8. Cf. AZEVEDO, Carlito. «O anjo boxeador tenta descrever uma cena», em Monodrama cit., pp. 118-119. 
valem» todas as imagens de imigrantes e manifestantes que pontuam este livro proeminentemente político de Carlito Azevedo, como figurações de experiências limítrofes, marcadas pelo risco.[9] Mas sobretudo, pela comunhão na violência física, na agressão ao corpo, parece se aproximar especialmente da imagem da «jovem / que se picava junto / à mureta do Aterro, / camiseta salpicada, / a seringa suja» (também ela, como se saberá depois, uma imigrante[10] ), de outro poema de Monodrama, imagem desoladora que suscita a asserção criticamente certeira, atribuída por Carlito a uma interlocutora não-identificada, de que «Nenhum poema / é mais difícil / do que sua época». O que é ainda uma maneira de dizer, com Pasolini, «Eu sei»: com todas as dificuldades («Eu sei. Mas não tenho as provas»), mas também todas as possibilidades («Eu sei porque sou um intelectual, um escritor, que busca [...] imaginar tudo o que não se sabe ou que se cala»), que esse saber, operador dialético entre a experiência e a escrita, implica, para o poeta não menos que para o leitor. A circunstância de fundo, em Carlito como em Saviano, é a de uma guerra civil, nunca de todo declarada, que acaba por se confundir com a própria vida e da qual ninguém sai completamente ileso: «eu disse: e é sempre / como um país / se dando conta / de que entrou / em guerra, um dia / um país se dá conta / de que a guerra / de que todos falam é / a sua guerra, o / país é o seu / país, e o que chamam / de a guerra é a / sua vida».[11] Daí - porque estamos em meio à conflagração, porque ainda não há como se saber com clareza quem são os vencedores e quem são os vencidos, e menos ainda se estamos entre os vencedores ou entre os vencidos - que às vezes não reste muito mais ao poeta que se deitar «sobre a grama» e se pôr «a escutar a / desconexão absoluta de / todas as falas do mundo, de / todos os sonhos do mundo».[12] O desafio que se coloca para o poeta, tanto quanto para qualquer um que se disponha a encarar e dizer seu próprio tempo, é o de conseguir transformar essa realidade hostil (essa vida que se dá a perceber como uma guerra, e que, precisamente por ser hostil, é atravessada dialeticamente pelo desejo, pelo sonho e pela utopia) em experiência: isto é, em matéria genuinamente vivida e potencialmente transmissível. Não por acaso, a mesma interlocutora que esclareceu o poeta sobre a relação entre a poesia e a sua época dirá, pouco adiante, «qualquer / coisa assim»: «como não tenho / mais questão alguma / com a metafísica, eu / não fico esperando por /

9. Cf. id., Monodrama cit., pp. 11-29 («Emblemas»), 73-85 («Dois estrangeiros»), 86-88 («Limpeza do aparelho»), 91-108 («Monodrama»).

10. Id., p. 47: «Você a reconheceu / como sendo a menina / coreana da Central / de Fotocópias do Catete / aquela com / camiseta salpicada / presilhas fluo / mureta / e hipodérmica pendente / do braço».

11. Id., pp. 35-36; cf. id., pp. 53-54, 57 («“É a guerra. É a guerra. É essa maldita guerra...”, ele entoava bem baixinho, resignado, tomando o rumo de volta para casa [...]»), 68-69, 71-72, 89-90, 121-134. Cf. SAVIANO, Roberto. Gomorra cit., p. 134: «Como na Bósnia, como na Argélia, como na Somália, como em qualquer confusa guerra interna, quando é difícil entender a que lado pertences, basta matar o teu vizinho, o cão, o amigo, ou um teu familiar. Um boato de parentesco [Una voce di parentela], uma semelhança é condição suficiente para se tornar alvo. Basta que passes por um rua para receber de pronto uma identidade de chumbo».

12. AZEVEDO, Carlito. «Pálido céu abissal», in Monodrama cit., p. 55. 
alguma presença para / experimentar o que / experimento, experimento / todos os dias».[13]

3. Não por acaso, também, o mais recente livro do historiador e filósofo da arte Georges Didi-Huberman, Survivance des lucioles[14], o qual constitui uma espécie de vindicação do poder de resistência política de certas imagens e certas palavras, parte de uma premissa semelhante: refuta-se a noção, que se acha, por exemplo, em alguns textos de Giorgio Agamben, de que a possibilidade da experiência encontra-se destruída para o homem contemporâneo.[15] E é significativo que Didi-Huberman comece seu livro pela releitura - francamente antitética e problematizadora - de um célebre ensaio de Pasolini, publicado, no mesmo Corriere della Sera, poucas semanas depois do já mencionado «Il romanzo delle stragi». Trata-se do ensaio que ficou conhecido como "L'articolo delle lucciole» (com este título foi recuperado nos Scritti corsari, embora, em sua forma primeira, de $1^{\circ}$ de fevereiro de 1975 , se intitulasse, mais prosaicamente, «Il vuoto del potere in Italia»).[16] Didi-Huberman busca pensar com Pasolini, sem se furtar, quando necessário, a pensar contra Pasolini (adotando postura semelhante frente a Agamben).

No seu texto - cujo título pode ser traduzido por «O artigo dos vagalumes» [17] -, Pasolini faz um diagnóstico extremamente desesperançado da sociedade italiana de sua época, a qual estaria sucumbindo a uma nova e, até há pouco, imprevisível forma de fascismo, de conseqüências talvez mais nocivas que o fascismo histórico (ou «fascismo fascista», para falar como o autor). Este «fascismo radicalmente, totalmente, imprevisivelmente novo» teria resultado de um «fenômeno» ocorrido na Itália dez anos antes, conforme data Pasolini. Em vez de simplesmente

\footnotetext{
13. Id., "O tubo», in Monodrama cit., pp. 33 e 42.

14. DIDI-HUBERMAN, Georges. Survivance des lucioles, Paris: Minuit, 2009.

15. Escreve Agamben, nas primeiras linhas do ensaio que dá título ao livro Infanzia e storia, citadas por DidiHuberman: «Todo discurso sobre a experiência deve hoje partir da constatação de que esta não é mais algo que nos seja ainda dado fazer. Porque, assim como foi privado da sua biografia, o homem contemporâneo foi expropriado da sua experiência: antes, a incapacidade de fazer e transmitir experiências é, talvez, um dos poucos dados certos de que ele dispõe sobre si mesmo». AGAMBEN, Giorgio. «Infanzia e storia. Saggio sulla distruzione dell'esperienza», in Infanzia e storia. Distruzione dell'esperienza e origine della storia (1978), nuova edizione accresciuta. Turim: Einaudi, 2001, p. 5.

16. PASOLINI, Pier Paolo. «Larticolo delle lucciole» (1975), in Scritti corsari cit., pp. 404-411.

17. Há uma tradução do texto, com o título de «O artigo dos pirilampos», in PASOLINI, Pier Paolo. Os jovens infelizes. Antologia de ensaios corsários, org. Michel Lahud, trad. Michel Lahud e Maria Betânia Amoroso, São Paulo: Brasiliense, 1990. Vagalume me parece preferível a pirilampo porque, embora tenha surgido como eufemismo para vaga-lume, sugere algo como luzes vagantes. Mas devemos lembrar que também temos em português a palavra lucíola (proveniente justo do italiano lucciola), a qual, embora não registrada nem no Aurélio nem no Houaiss, encontra-se no Caldas Aulete ( "gênero de insetos coleópteros teleforídeos das regiões quentes da Europa; são brilhantes de noite»), com uma abonação extraída de Fagundes Varela: «As mil constelações se tresmalham quais errantes lucíolas». Vale lembrar que a palavra também aparece no título do célebre romance de José de Alencar.
} 
descrever tal fenômeno com o léxico da política ou da sociologia, Pasolini (justificando assim fazê-lo por ser «um escritor, e escrev[er] em polêmica») busca circunscrevê-lo por meio de «uma definição de caráter poético-literário» - ou seja, por meio de uma imagem:
Nos primeiros anos Sessenta, por causa da poluição do ar, e, sobretudo, no campo, por causa da poluição da água (os rios azuis e os canais transparentes), começaram a desaparecer os vagalumes. O fenômeno foi fulminante e fulgurante. Depois de poucos anos os vagalumes não existiam mais. (São agora uma recordação, bastante aflitiva, do passado: e um homem velho que tenha uma tal recordação não pode reconhecer, nos novos jovens, a si mesmo quando jovem, e portanto não pode mais ter as belas saudades de um dia.)[18]

Como nota Didi-Huberman, Pasolini não recorre a esta «imagem poéticoecológica» para «suavizar a violência do fenômeno» que diagnosticou, mas, sim, para «insistir na dimensão antropológica - a seus olhos a mais profunda, a mais radical - do processo político em questão»: o desaparecimento dos vagalumes (la scomparsa delle lucciole) corresponderia, no plano cultural, a nada menos que (a hipérbole é pasoliniana) um "genocídio».[19] Pasolini descreve esse processo em três fases. Antes do desaparecimento dos vagalumes, era "completa e absoluta» a «continuidade entre fascismo fascista e fascismo democrata-cristão». «A democracia que os antifascistas democrata-cristãos opunham à ditadura fascista eram despudoradamente formal»: os mesmos «códigos» continuavam ativos, a mesma "violência policial», o mesmo «desprezo pela Constituição».[20] O regime sustentava-se numa maioria absoluta que congregava amplos estratos das classes médias e das massas camponesas, sob a tutela do Vaticano. Os «"valores" que contavam» permaneciam os mesmos da época fascista: «a Igreja, a pátria, a família, a obediência, a disciplina, a ordem, a poupança, a moralidade». Eram «valores», frisa Pasolini, «também reais», isto é, «pertenciam às culturas particulares e concretas que constituíam a Itália arcaicamente agrícola e paleoindustrial»; porém, «no momento em que eram assumidos como "valores" nacionais não podiam senão perder toda realidade», tornando-se um «atroz, estúpido, repressivo conformismo de Estado». Diante desse quadro, mesmo os «intelectuais» e os «opositores» nutriam «insensatas esperanças»: «Esperava-se que tudo aquilo não fosse completamente verdadeiro, e que a democracia formal

\footnotetext{
18. PASOLINI, Pier Paolo. «L'articolo delle lucciole» cit., pp. 404-405.

19. DIDI-HUBERMAN, Georges. Survivance des lucioles cit., p. 23. PASOLINI, Pier Paolo. «Larticolo delle lucciole» cit., p. 407.
}

20. PASOLINI, Pier Paolo. «L'articolo delle lucciole» cit., p. 405. 
contasse no fundo alguma coisa».[21] Pasolini passa então à descrição da segunda fase, simultânea ao desaparecimento dos vagalumes. Neste período, «o grande país que estava se formando dentro do país - isto é, a massa operária e camponesa organizada pelo PCI [Partido Comunista Italiano] - [tanto quanto] os intelectuais, mesmo os mais avançados e críticos, não se aperceberam que "os vagalumes estavam desaparecendo"».[22] Este desconhecimento, segundo Pasolini, poderia se atribuir ao fato de se dispor, então, apenas de informações fornecidas pela investigação sociológica, que «eram informações ainda não vividas, em substância formalistas» (volta-se, pois, à questão da experiência como fundamento de um saber radical): «Ninguém podia suspeitar a realidade histórica que seria $\mathrm{o}$ imediato futuro [...] [23] Por fim, advém a terceira fase, «após o desaparecimento dos vagalumes», na qual é impossível fechar os olhos para a realidade hostil: agora, os " "valores" nacionalizados e, portanto, falsificados», provenientes do «velho universo agrícola e paleocapitalista», já não contam - «e não servem mais nem mesmo enquanto falsos». "A substituir-lhes, estão os "valores" de um novo tipo de civilização, totalmente "outra" em relação à civilização camponesa e paleoindustrial. [...] trata-se da primeira "unificação" real sofrida pelo nosso país [...].»[24] Enquanto em outros países houve uma passagem gradual de um modelo civilizacional a outro, na Itália o processo foi abrupto e extremamente destrutivo. «O trauma italiano do contato entre a "arcaicidade" pluralista e o nivelamento industrial tem talvez um único precedente: a Alemanha antes de Hitler. Também aqui os valores das diversas culturas particulares [culture particolaristiche] foram destruídos pela violenta homologação da industrialização: com a conseqüente formação daquelas enormes massas, não mais antigas (camponesas, artesãs) e não ainda modernas (burguesas), que constituíram o selvagem, aberrante, imponderável corpo das tropas nazistas.»[25] O prognóstico não poderia ser mais desanimador e mesmo apocalíptico:

\footnotetext{
$\mathrm{Na}$ Itália está acontecendo algo semelhante: e com ainda maior violência, dado que a industrialização dos anos setenta constitui uma "mutação" decisiva mesmo com relação àquela alemã de cinqüenta anos antes. Não estamos mais defronte, como todos já sabem, a "tempos novos", mas a uma nova época da história humana: daquela história humana cujos prazos são milenares [le cui scadenze sono millenaristiche]. Era impossível que os italianos reagissem pior que assim a tal trauma histórico. Estes se tornaram em
}
21. Id., pp. 405-406
22. Id., p. 406.
23. Id., pp. 406-407
24. Id., p. 407.
25. Id., ibid. 
poucos anos (especialmente no Centro-sul) um povo degenerado, ridículo, monstruoso, criminoso.[26]

Esta «mutação» sócio-política, e mesmo antropológica, e o «trauma» dela decorrente são particularmente sensíveis para quem sempre enxergou nas tradições e práticas do povo da velha Itália camponesa formas de resistência ao progresso uniformizador e totalitário. Um homem imbuído de tal «amor» por seu povo não podia senão interpretar a vertiginosa conversão dos italianos em massa consumidora como uma catástrofe ou um «genocídio»:

\footnotetext{
«Vi, portanto, "com os meus sentidos" ["coi miei sensi"] o comportamento imposto pelo poder dos consumos recriar e deformar a consciência do povo italiano, até uma irreversível degradação. O que não acontecera durante o fascismo fascista, período em que o comportamento era completamente dissociado da consciência. Infrutiferamente o poder "totalitário" iterava e reiterava as suas imposições comportamentais: a consciência não estava implicada aí. Os “modelos” fascistas não eram senão máscaras, a se colocar e tirar. Quando o fascismo fascista caiu, tudo voltou a ser como era».[27]
}

Daí que Pasolini assevere drasticamente que «a distinção entre o fascismo fascista e o fascismo desta segundo fase do poder democrata-cristão não só não tem comparações na nossa história, mas provavelmente em toda a história».[28]

E daí também que, levando ao extremo as reflexões já ensaiadas em textos anteriores igualmente lembrados por Didi-Huberman[29], desenvolvesse os temas do «verdadeiro fascismo» e do "genocídio» até chegar, pouco depois da publicação do artigo sobre o desaparecimento dos vagalumes, à conclusão radical de que foi antes de tudo o próprio ser humano que desapareceu na sociedade contemporânea. Numa entrevista publicada seis dias depois de seu assassinato, Pasolini dizia ao jornalista: «Pretendo que você olhe em torno e se dê conta da tragédia. Qual é a tragédia? A tragédia é que não existem mais seres humanos, existem estranhas máquinas que se batem umas contra as outras».[30] DidiHuberman sintetiza muito bem o que está em jogo nessa justaposição de figuras em desaparição:

\footnotetext{
26. Id., pp. 407-408.

27. Id., p. 408

28. Id., ibid.

29. Id., «Acculturazione e acculturazione» (1973), «Il vero fascismo e quindi il vero antifascismo» (1974) e «Il genocidio» (1974), in Scritti corsari cit., pp. 290-293, 313-318 e 511-517.

30. Id., «Siamo tutti in pericolo» (1975), em Saggi sulla politica e sulla società cit., p. 1724.
} 
É preciso então compreender que o improvável e minúsculo esplendor dos vagalumes, aos olhos de Pasolini - esses olhos que sabiam tão bem contemplar um rosto ou deixar se manifestar [déployer] o gesto justo no corpo de seus amigos, de seus atores -, não metaforiza nada mais do que a humanidade por excelência, a humanidade reduzida à sua mais simples potência de nos fazer sinais dentro da noite [l'humanité réduite à sa plus simple puissance de nous faire signe dans la nuit].[31]

4. Contra a noção de uma absoluta aniquilação da humanidade, condensada poeticamente na imagem do desaparecimento dos vagalumes, Didi-Huberman afirma que «uma coisa é indicar a máquina totalitária, uma outra é lhe conceder tão rapidamente uma vitória definitiva e sem volta».[32] Ou seja, ainda que estejamos envolvidos e dominados pelas trevas do totalitarismo mais insidioso (porque não se mostra imediatamente como tal) ou, sobretudo, pelos complementares clarões do espetáculo triunfante, a humanidade ou, para usar uma expressão cara ao autor, os «povos» (peuples)[33] preservaram a capacidade de emitir seus sinais de resistência e esperança. E é, antes de mais, no próprio Pasolini que Didi-Huberman descobre uma abertura a estes sinais: «toda a obra literária, cinematográfica e mesmo política de Pasolini parece atravessada [semble bien traversée] por tais momentos de exceção onde os seres humanos se tornam vagalumes - seres luminescentes, dançantes, erráticos, inapreensíveis e, como tais, resistentes - sob nosso olhar maravilhado».[34]

Os próprios vagalumes, afinal, não desapareceram de todo. Eles reaparecem, por exemplo, para o poeta e fotógrafo Denis Roche, que, num livro intitulado, certamente em homenagem a Pasolini, La disparition des lucioles, reproduz um fragmento de diário, datado de 3 de julho de 1981, no qual registra uma noite passada entre amigos nos campos da Itália: cerca de vinte vagalumes iluminamse junto às folhagens, provocando exclamações dos convivas, para logo mais desaparecerem novamente na escuridão.[35] E os vagalumes aparecem também para o próprio Didi-Huberman, que rememora a época em que viveu em

\footnotetext{
31. DIDI-HUBERMAN, Georges. Survivance des lucioles cit., p. 25.

32. Id., p. 35 .

33. É o título do quarto capítulo de Survivance des lucioles cit., p. 77-97. Cf. também id., «Peuples exposés (à disparaître)», Chimères, 66-67 (2008) [Morts ou vifs], pp. 21-42 ; id., «Pasolini ou la recherche des peuples perdus», Les Cahiers du Musée Nationale d’Art Moderne, 108 (été 2009), pp. 86-115; id., «Peuples exposés, peuples figurants», De(s)générations, 9 (septembre 2009) [Figure, figurants], pp. 7-17.

34. Id., Survivance des lucioles cit., p. 19.

35. ROCHE, Denis. La disparition des lucioles (réflexions sur l'acte photographique). Paris: Éditions de l'Étoile, 1982. Citado por DIDI-HUBERMAN, Georges. Survivance des lucioles cit., pp. 37-40.
} 
Roma, dez anos depois da morte de Pasolini, quando, na colina do Pincio, mais precisamente num local conhecido como «bosque dos bambus», havia «uma verdadeira comunidade de vagalumes» a fascinar os passantes: «os vagalumes não tinham desaparecido entre 1984 e 1986, mesmo em Roma, mesmo no coração urbano do poder centralizado».[36] No entanto, conta Didi-Huberman que, mais recentemente, retornou ao Pincio e constatou que os bambus haviam sido cortados e que os vagalumes haviam, outra vez, desaparecido.[37] Porém, seguramente para voltar a aparecer em outro lugar. Se queremos ver de novo os vagalumes, num tempo em que a sua sobrevivência toma a forma de «uma comunidade anacrônica e atópica», precisamos saber a hora de nos deslocarmos, de mudarmos de posição: trata-se, afinal, de uma «iluminação intermitente» (éclairage intermittent) que é também uma «iluminação em movimento» (éclairage en mouvement), uma iluminação fugidia no tempo e no espaço.[38] Se há, segundo Deleuze e Guattari, uma «literatura menor» (representada por Kafka), haveria também, propõe Didi-Huberman, uma «luz menor» (lumière mineure) que possui «as mesmas características filosóficas» daquela: do «forte coeficiente de desterritorialização» às premissas de que «tudo aí é político»e «tudo adquire um valor coletivo», falando do povo e das «condições revolucionárias» inerentes à sua marginalização.[39]

Podemos nos perguntar se não é precisamente esta «luz menor» que Roberto Saviano e Carlito Azevedo foram buscar nas palavras, nas imagens e sobretudo na figura de Pasolini. Se não a luz dos vagalumes, a luz dos fogos-fátuos que, em certas noites do campo, desprendem-se dos cadáveres e fazem pensar em fantasmas, em aparições. Afinal, qualquer exame atento das artes de nossa «época», pelo menos em suas mais interessantes realizações, demonstra que nelas a crítica da contemporaneidade não se dissocia do que poderíamos chamar de uma estética, que é também uma política, da assombração. Que é igualmente, antes de tudo, uma poética da sobrevivência, se por «sobrevivência» compreendemos a forma extrema de comunicação e indeterminação entre vivos e mortos - mas também, em analogia com esta, a dinâmica trans-histórica intrínseca às artes, e, antes que a elas, a todas as imagens, artísticas e nãoartísticas.[40] Sobrevive-se a um morto ou sobrevive-se à própria morte: em

\footnotetext{
36. DIDI-HUBERMAN, Georges. Survivance des lucioles cit., p. 40.

37. Id., ibid.

38. Id., pp. 42 e 39.

39. DELEUZE, Gilles; GUATTARI, Félix. Kafka. Pour une littérature mineure. Paris: Minuit, 1975, pp. 29-33. Cf. Georges Didi-Huberman, Survivance des lucioles cit., p. 44.

40. Cf. Georges Didi-Huberman, L'image survivante. Histoire de l'art et temps des fantômes selon Aby Warburg, Paris: Minuit, 2002.
} 
ambos os casos, é toda uma vida espectral, tão afim à «condição póstuma da literatura» [41] (e das artes em geral), que aí se inicia. Não por acaso, já num de seus primeiros poemas, Carlito Azevedo confrontava o leitor com a figura ambígua ou limítrofe do «vivente morrente».[42] Isto é: do sobrevivente. Isto é: do resistente - da resistência.

EDUARDO STERZI é professor do Instituto de Estudos da Linguagem da Unicamp e autor de Por que ler Dante (Globo), A prova dos nove (Lumme) (ensaios) e Aleijão (7 Letras) (poemas).

41. Cf. FERRONI, Giulio. Dopo la fine. Sulla condizione postuma della letteratura, Torino: Einaudi, 1996.

42. AZEVEDO, Carlito. «A dúvida de Camilo Pessanha», in Collapsus linguae, p. 40. Cf. PESSANHA, Camilo. «Água morrente» [título atribuído por João de Castro Osório] (1895), in Clepsydra, ed. Paulo Franchetti, Campinas: Editora da Unicamp, 1994, p. 100. 